\title{
Aspiration-sclerotherapy Results in Effective Control of Liver Volume in Patients with Liver Cysts
}

\author{
Loes van Keimpema · Daan B. de Koning • \\ Simon P. Strijk · Joost P. H. Drenth
}

Received: 24 September 2007 / Accepted: 5 November 2007/Published online: 26 February 2008

(C) The Author(s) 2008

\begin{abstract}
Purpose To study the extent to which aspiration-sclerotherapy reduces liver volume and whether this therapy results in relief of symptoms. Results Four patients, group I, with isolated large liver cysts, and 11 patients, group II, with polycystic livers, underwent aspirationsclerotherapy. Average volume of aspirated cyst fluid was $1,044 \mathrm{ml}$ (range 225-2,000 ml) in group I and 1,326 ml (range 40-4,200 ml) in group II. Mean liver volume before the procedure was $2,157 \mathrm{ml}$ (range 1,706-2,841 ml) in group I and 4,086 $\mathrm{ml}$ (range 1,553-7,085 ml) in group II. This decreased after the procedure to $1,757 \mathrm{ml}$ (range $1,479-2,187 \mathrm{ml}$ ) in group I. In group II there was a statistically significant decrease to $3,347 \mathrm{ml}$ (range 1,249$6,930 \mathrm{ml}, P=0.008$ ). Volume reduction was $17.1 \%$ (range $-34.7 \%$ to $-4.1 \%$ ) and $19.2 \%$ (range $-53.9 \%$ to $+2.4 \%$ ) in groups I and II, respectively. Clinical severity of all symptoms decreased, except for involuntary weight loss and pain in group II. Conclusion Aspiration-sclerotherapy is an effective means of achieving liver volume reduction and relief of symptoms.
\end{abstract}

Keywords Liver cyst - PCLD - Aspiration - Ethanol · Volumetry

L. van Keimpema $(\bowtie)$. D. B. de Koning · J. P. H. Drenth Department of Gastroenterology and Hepatology, University Medical Center St. Radboud, P.O. Box 9101, 6500 HB

Nijmegen, The Netherlands

e-mail: L.vanKeimpema@MDL.umcn.nl

\section{S. P. Strijk}

Department of Radiology, University Medical Center St. Radboud, P.O. Box 9101, 6500 HB Nijmegen, The Netherlands

\section{Introduction}

Isolated liver cysts are very frequent-they have been detected in up to $18 \%$ of patients subjected to ultrasonography or CT scan [1-3]. Liver cysts have been recognized increasingly as the routine use of imaging studies has become more widespread. The phenotype of a number of inherited syndromes dictates the presence of hepatic cysts. Radiographically, hepatic cysts in polycystic livers share the same architecture and are thought to arise from aberrant bile ducts [4].

Polycystic liver disease (PCLD) is an autosomal inherited condition characterized by the presence of numerous cysts scattered throughout the liver. There are no, or only a few, cysts in the kidneys, which distinguishes it from autosomal dominant polycystic kidney disease (ADPKD), the most common cause of polycystic liver disease [4]. Although the hepatic phenotype of both syndromes is similar, the syndromes are separate entities, as is illustrated by the fact that both have different causative genes. PCLD is caused by mutations in the PRKCSH gene and the SEC63 gene [5, 6] whereas ADPKD is caused by mutations in the $P K D-1$ and the PKD-2 genes [7]. PCLD probably results from ductal plate malformation, which is characterized by a disturbance in the physiological remodeling of the ductal plate [8]. The multiple cysts arise from progressive dilatation of the abnormal ducts in biliary hamartomas [4], which are the result of ductal plate malformation at the level of the small intrahepatic bile ducts. These small bile ducts have lost continuity with the remaining biliary tree, which explains the non-communicating nature of the cysts in PCLD [9].

Hepatic cysts are rarely symptomatic. Symptoms can arise due to growth of the cysts and are usually due to abdominal mass; examples include abdominal pain, early satiety, dyspnea, nausea, and vomiting and are mostly seen in females 
$>50$ years of age. Rarely, complications such as portal hypertension, cyst infection, and cyst rupture occur [10].

The majority of patients with multiple liver cysts are not in need of therapy. When patients become symptomatic, therapeutic options should be explored. The aim of therapy is to reduce cyst volume in order to achieve relief of symptoms and to prevent recurrence. Current management consists of aspiration-sclerotherapy of selected cysts or surgical approaches aimed at excising or obliterating cysts [11]. Choice of treatment of PCLD is based on the number, size, and location of the cysts and on local expertise.

Aspiration-sclerotherapy is a minor invasive option with low morbidity. The technique was first described in 1985 [12] after the realization that aspiration alone led to $100 \%$ recurrence of cysts [13]. Improvement of this procedure consists in additional sclerotherapy with ethanol or other irritants (antibiotics), after aspiration of the cyst contents, aimed at destroying the cyst lining epithelium [12, 14-16].

Though this method has slowly gained popularity, it is unknown if and to what extent it reduces liver volume, as this is arguably the main reason for the development of symptoms. Furthermore, it is unknown whether this treatment actually benefits patients in terms of relief of symptoms.

To this end we designed this study with two aims in mind. First we aimed to evaluate the efficacy of aspirationsclerotherapy in reduction of liver volume. Second we wanted to know whether symptoms experienced by patients with polycystic liver disease or large isolated hepatic cysts were improved by the procedure.

\section{Material and Methods}

\section{Subjects}

Between October 2004 and May 2007, 15 symptomatic patients underwent ultrasonographically guided aspirationsclerotherapy. Patients were subdivided into two groups. Group I included four patients with isolated large liver cysts (two male, two female, mean age 51.3 years (SD 27.6, range 24-76 years)). Group II included 11 patients with PCLD, defined as $>15$ liver cysts (all female, mean age 55.0 years (SD 12.7, range 35-81 years)). Four patients of group II, carried a PRKCSH gene mutation and none of them had a SEC63 gene mutation. The study was approved by the local medical ethical review committee (CMO regio Arnhem Nijmegen). All participants provided informed consent.

\section{Procedure}

All aspiration-sclerotherapy procedures to treat liver cysts were performed on an out-patient basis. Patients were put in a supine position. After locating a strategically located symptomatic cyst, the overlying skin was locally anaesthetized with lidocaine and a small incision was made. We performed ultrasound guided aspiration of the cyst with a 5 French straight catheter needle system or a 7 French pigtail needle system. The cyst was emptied via a three-way stopcock without allowing air to enter the collapsed cyst. After emptying the cyst, we proceeded to instill $96 \%$ ethanol (to a maximum of $27 \%$ of total aspirated volume). We usually inject and evacuate ethanol several times in order to ensure maximal ablation of the cystic wall. After 15 min (range 10-20 $\mathrm{min}$ ) the procedure was terminated by evacuation of all remaining ethanol and removal of the catheter. If a patient experienced pain or complete aspiration of cyst fluid was not possible, in most instances because of the presence of cystic blood clots, no ethanol was instilled into the cyst and the session was abandoned.

\section{Volumetry}

Each patient undergoing aspiration-sclerotherapy was subjected to two multidetector computed tomography (CT) scans, before and after treatment, with a maximum interval of 18 months between the scans. Liver volumetry was performed on the multidetector CT-scan (Siemens Somatom Sensation 64) before the first session and, if there were more sessions, after the last session.

The digital CT images with $3 \mathrm{~mm}$ slice thickness were used for digital volumetry, using the Siemens Volume application. The liver was outlined manually, marking each $1-5 \mathrm{~cm}$ with a mouse click until the entire liver perimeter was outlined. This step was repeated each $9 \mathrm{~mm}$ through the complete length of the liver. The software intrapolated the intermediate slices and calculated the areas within the indicated circumference. Finally, the software calculated the liver volume by use of the equation $V=S \times A$, where $S$ is the interval of the serial slices (mm) and $A$ is the enclosed area $\left(\mathrm{cm}^{2}\right)$. For comparison, four normal livers were evaluated. We measured four livers from four subjects that had had a CT scan for liver-unrelated reasons. There the average normal liver volume was $1,550 \mathrm{ml}$ (range 1,230-1,751 ml). The average difference between intraindividual observations was $35 \mathrm{ml}$ (range 2-85 ml), measured in seven livers. That between interindividual observations was $52 \mathrm{ml}$ (range 38-72 ml), measured in four livers.

\section{Questionnaire}

Patients were asked to complete a questionnaire with 12 abdomen-symptom-specific items. This symptom-based 
questionnaire was focused on the period before, during, and after treatment [17]. It is a self-completed questionnaire, that has been validated, and can be used in a variety of clinical settings. This questionnaire included questions about the severity of the symptoms during the previous 4 weeks rated on a seven-point Likert scale (with 0 meaning "absent" and 6 "very severe"). A score of two or more was regarded as symptom presence. Furthermore, demographic variables, duration of symptoms, and overall severity (on a $100 \mathrm{~mm}$ visual analogue scale) were recorded. Questions that were not completed properly were excluded from further analysis.

\section{Statistical Analysis}

Paired $t$-tests were performed to study differences between liver volume before and after the procedure and the severity of symptoms. Pearson's correlation coefficient was used to compare the amount of aspirated fluid and liver volume reduction. A difference with a $P$-value of $<0.05$ was considered statistically significant.

\section{Results}

Patients

Patient characteristics are shown in Table 1. No session was terminated prematurely because of pain.
In total there were six aspiration-sclerotherapy sessions in group I and 23 in group II. A total of 30 cysts were aspirated in group II. Two patients in group I and five in group II were subjected to a single session, while the remaining two and six had from two to four sessions. In group II, we aspirated a maximum of two cysts during each session. Figure 1 shows a typical result of the aspirationsclerotherapy (patient 3). Here, the procedure led to a decrease in volume of $11.6 \%$.

The average volume of aspirated cyst fluid was $1,044 \mathrm{ml}$ (SD 729, range 225-2,000 ml) in group I and 1,326 $\mathrm{ml}$ (SD 1194 , range 40-4,200 ml) in group II. The average amount of ethanol instilled in the cysts was $5.7 \%$ of aspirated volume (range 1.6-13.3\%) in group I and $8.3 \%$ (range $0.7-$ $27 \%$ ) in group II but never more than $50 \mathrm{ml}$.

Mean clinical follow-up period after the last session was 21 months (range 8-30 months) for group I and 14.5 months (range 3-27 months) for group II. Four patients, one of group I and three of group II, were referred for laparoscopic fenestration because of failure of symptoms to improve.

\section{Volumetry}

Average liver volume before the procedure, $2,157 \mathrm{ml}$ (range 1,706-2,841 ml) in group I and 4,086 $\mathrm{ml}$ (range $1,553-7,085 \mathrm{ml}$ ) in group II, was (statistically) much higher than that of control livers, because of the large volumes of cystic livers. Average liver volume decreased

Table 1 Patient characteristics

a Age reflects current age

b Indicates a $P R K C S H$ mutation

a Age reflects current age
b Indicates a $P R K C S H-$
mutation

\begin{tabular}{|c|c|c|c|c|c|c|c|c|}
\hline & Sex & $\mathrm{Age}^{\mathrm{a}}$ & Diagnosis & $\begin{array}{l}\text { Number of } \\
\text { sessions }\end{array}$ & $\begin{array}{l}\text { Total aspirated } \\
\text { cyst fluid }(\mathrm{ml})\end{array}$ & $\begin{array}{l}\text { CT-volume } \\
\text { before }(\mathrm{ml})\end{array}$ & $\begin{array}{l}\text { CT-volume } \\
\text { after (ml) }\end{array}$ & $\begin{array}{l}\text { Liver volume } \\
\text { change }(\%)\end{array}$ \\
\hline \multicolumn{9}{|c|}{ Group I } \\
\hline 1 & $\mathrm{~F}$ & 24 & Single cysts & 2 & 950 & 1,801 & 1,479 & -17.9 \\
\hline 2 & M & 31 & Single cysts & 2 & 1,000 & 2,281 & 2,187 & -4.1 \\
\hline 3 & M & 74 & Single cysts & 1 & 225 & 1,706 & 1,508 & -11.6 \\
\hline 4 & $\mathrm{~F}$ & 76 & Single cysts & 1 & 2,000 & 2,841 & 1,855 & -34.7 \\
\hline \multicolumn{9}{|c|}{ Group II } \\
\hline $5^{b}$ & $\mathrm{~F}$ & 40 & PCLD & 4 & 1,310 & 5,489 & 4,974 & -9.4 \\
\hline $6^{\mathrm{b}}$ & $\mathrm{F}$ & 58 & PCLD & 4 & 505 & 4,897 & 4,145 & -15.4 \\
\hline 7 & $\mathrm{~F}$ & 65 & PCLD & 1 & 40 & 1,553 & 1,441 & -7.2 \\
\hline 8 & $\mathrm{~F}$ & 81 & PCLD & 1 & 1,400 & 3,004 & 2,424 & -19.3 \\
\hline $9^{\mathrm{b}}$ & $\mathrm{F}$ & 55 & PCLD & 1 & 1,300 & 4,195 & 2,877 & -31.4 \\
\hline $10^{\mathrm{b}}$ & $\mathrm{F}$ & 35 & PCLD & 3 & 980 & 4,275 & 4,376 & +2.4 \\
\hline 11 & $\mathrm{~F}$ & 61 & PCLD & 2 & 1,100 & 2,809 & 2,164 & -23.0 \\
\hline 12 & $\mathrm{~F}$ & 45 & PCLD & 1 & 500 & 6,959 & 6,930 & -0.4 \\
\hline 13 & $\mathrm{~F}$ & 60 & PCLD & 2 & 4,200 & 7,085 & 4,637 & -34.6 \\
\hline 14 & $\mathrm{~F}$ & 57 & PCLD & 1 & 200 & 1,974 & 1,603 & -18.8 \\
\hline 15 & $\mathrm{~F}$ & 48 & PCLD & 3 & 3,050 & 2,707 & 1,249 & -53.9 \\
\hline
\end{tabular}



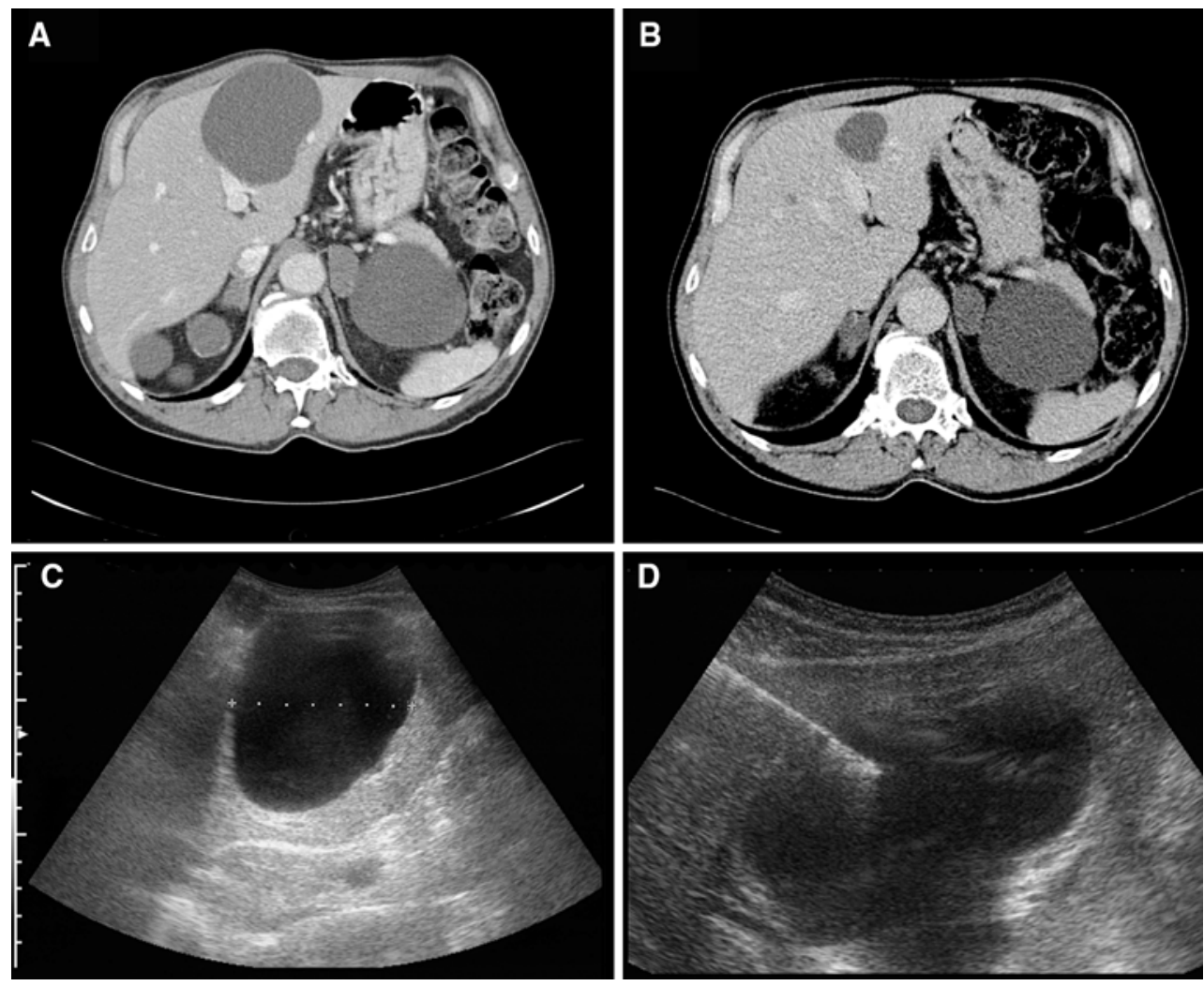

Fig. 1 (a) CT scan of the liver of a 74-year-old man with ADPKD and a large isolated cyst. (b) CT scan of the same region of the liver 4 months later shows a regression of the isolated cyst. (c) Ultrasound of the same cyst before aspiration. (d) Ultrasound-guided aspiration of the cyst

to $1,757 \mathrm{ml}$ (range $1,479-2,187 \mathrm{ml}$ ) in group $\mathrm{I}$ and $3,347 \mathrm{ml}$ (range 1,249-6,930 $\mathrm{ml}$ ) in group II after the procedures. This represents a reduction of volume of $17.1 \%$ (range $-34.7 \%$ to $-4.1 \%$ ) in group I and $19.2 \%$ (range $-53.9 \%$ to $+2.4 \%)$ in group II. Liver volume reduction reached statistical significance in group II with a mean liver volume decrease of $739 \mathrm{ml}$ (95\%CI $236-1,241 \mathrm{ml}$, $P=0.008$ ). Liver volume decreased in all patients of group I and in nine patients in group II. One patient had only a slight decrease of liver volume and one patient had a slight increase.

There was an excellent, significant, correlation between the volume removed by cyst aspiration and the final liver volume as assessed on follow-up CT scanning. In essence, larger volume on aspiration led to better results in terms of liver volume reduction $(r=-0.87 P<0.0001)$ (Fig. 2).

\section{Questionnaire}

The response to the questionnaire was $100 \%$. Table 2 shows the average degree of symptoms during treatment. There were two patients, both of group II, which did not experience any pain during treatment. Nausea and vomiting was noted by three patients, two of group I and one of group II.

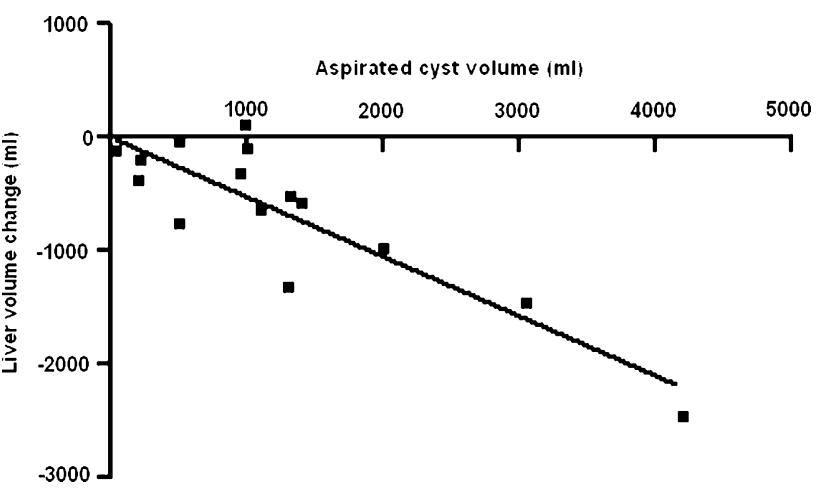

Fig. 2 Relationship between total aspirated cyst fluid and the liver volume $(r=-0.86, P<0.0001)$

Table 3 displays the average degree of symptoms before and after treatment. In both groups, the clinical severity of all symptoms decreased, except for involuntary weight loss and pain in group II. Specifically, the severity of postprandial fullness and abdominal distension decreased more than that of the other symptoms. Most patients of both groups experienced a decrease of all listed symptoms, although some patients had an increase of one of the symptoms after treatment. Total pain increased in four patients (all in group II), was stable in three (one in group I and two in group II), while the remaining patients had a decrease in total pain. 
Table 2 The average severity of symptoms during treatment

\begin{tabular}{lll}
\hline Symptom $^{\mathrm{a}}$ & Group I & Group II \\
\hline 1. Pain & & \\
$\quad$ Insertion of catheter & 2.7 & 2.0 \\
$\quad$ During aspiration & 2.8 & 1.5 \\
$\quad$ During ethanol instillation & 1.8 & 2.2 \\
2. Nausea & 0.9 & 0.5 \\
3. Vomiting & 0.7 & 0.3 \\
\hline
\end{tabular}

a Symptoms were scored on a range of $0-6(0=$ no symptom; $6=$ very severe)

None of the differences reached the level of statistical significance.

\section{Discussion}

We found that aspiration-sclerotherapy in patients with liver cysts leads to a substantial reduction of liver volume and a corresponding decline of symptoms. It is minimally invasive and safe, can be done on an out-patient basis, and complications are rare. The therapy is effective for single liver cysts and for polycystic livers with large cysts, because it reduces liver volume and probably relieves

Table 3 Average severity of symptoms before and after treatment

\begin{tabular}{|c|c|c|c|c|}
\hline \multirow[t]{2}{*}{ Symptom $^{\mathrm{a}}$} & \multicolumn{2}{|c|}{ Group I } & \multicolumn{2}{|c|}{ Group II } \\
\hline & Before & After & Before & After \\
\hline \multicolumn{5}{|l|}{ 1. Abdominal pain } \\
\hline General & 1.7 & 1.0 & 0.9 & 0.6 \\
\hline Postprandial & 1.7 & 0.7 & 1.0 & 0.4 \\
\hline Fasting & 1.3 & 0.7 & 0.6 & 0.3 \\
\hline Unrelated to defecation & 0.7 & 0 & 0.8 & 0.3 \\
\hline \multicolumn{5}{|l|}{ 2. Epigastric pain } \\
\hline General & 1.2 & 0.3 & 1.7 & 1.5 \\
\hline During daytime & 0.8 & 0.2 & 1.5 & 1.5 \\
\hline At night/asleep & 1.0 & 0.3 & 1.4 & 1.4 \\
\hline 3. Heartburn & 0 & 0 & 1.6 & 1.0 \\
\hline 4. Regurgitation & 0 & 0 & 1.6 & 1.2 \\
\hline 5. Nausea & 0.7 & 0.3 & 1.1 & 1.0 \\
\hline 6. Vomiting & 0.7 & 0.3 & 0.2 & 0.2 \\
\hline 7. Loss of appetite & 1.2 & 0.5 & 1.5 & 1.2 \\
\hline 8. Postprandial fullness & 1.3 & 0.8 & 3.0 & 2.1 \\
\hline 9. Shortness of breath & 0.7 & 0.2 & 1.0 & 0.7 \\
\hline 10. Abdominal distension & 2.0 & 0.7 & 3.2 & 1.7 \\
\hline 11. Involuntary weight loss & 0.3 & 0 & 0.3 & 0.7 \\
\hline 12. Pain & 2.1 & 1.3 & 1.4 & 1.6 \\
\hline
\end{tabular}

a Symptoms were scored on a range of 0-6 $(0=$ no symptom, $6=$ very severe) symptoms. This will make aspiration-sclerotherapy part of the armamentarium to treat PCLD and large solitary liver cysts.

We evaluated four livers with a single cyst and 11 polycystic livers. The procedure as described in this study resulted in an average liver volume reduction of $17.1 \%$ and $19.2 \%$, respectively. We elected not to treat patients with small liver cysts as it is unlikely this would result in substantial reduction of liver volume.

An interesting difference between the two groups is the total liver volume. The volumes of livers with a single cyst, are smaller than polycystic livers. We found that the efficacy of the aspiration-sclerotherapy in terms of liver volume reduction was similar in both groups.

We evaluated total liver volume rather than individual cysts, because symptoms in, especially, patients with polycystic livers arise from compression by severe hepatomegaly rather than the volume effect of a single strategically located cyst. As such, our study stands out because previously studies recorded the size of individual cysts rather than total liver volume. Liver volume measurement is used for the work-up for liver transplant. In our hands the measurement was reproducible, and had limited intra and interoperator variability. Although the procedure is currently not used in clinical practice it provides highly useful information and in the near future might be used to tailor the treatment options for PCLD [18-20].

The efficacy of the aspiration-sclerotherapy exceeded our expectation and could be achieved in all except a single patient of group II. The liver volume of this patient increased with by $2 \%$, despite an aspirated volume of $980 \mathrm{ml}$. At the moment it is uncertain why this single cyst was refractory to treatment. She was among two other patients of group II and one of group I who were referred for subsequent laparoscopic cyst fenestration.

We learned from our study that it is far more effective to evacuate large liver cysts (arbitrarily defined as $>8 \mathrm{~cm}$ ) as these lead to a significantly better volume reduction (Fig. 2). On the other hand, repeated (2-3) aspirations of these cysts are necessary to yield an acceptable volume reduction. In our hands the procedure does not lead to complete obliteration of the cyst but rather prevents it from expanding. For example, we were able to decrease large liver cysts $(>20 \mathrm{~cm})$ to less than $5 \mathrm{~cm}$ with adequate symptom control.

We used a questionnaire to score the severity of symptoms. Overall, there was an average decrease in the severity of symptoms. Abdominal distension and postprandial fullness were among the symptoms that were scored, in both groups, as most severe before treatment. These symptoms decreased after treatment. Moreover, most patients experience pain relief. 
Apart from pain, we observed no complications such as infection of liver cysts or pleural fluid effusion [16]. Pain could occur at any time during the procedure-when the catheter passes the liver capsule, upon fluid aspiration, and, finally, after injection of ethanol in the cyst. Patients describe the pain during ethanol instillation as a burning, but in most instances that abates quickly. Pain is seen in all studies as most common drawback of aspiration [12, 14, 16, 21-26].

Aspiration-sclerotherapy has several advantages over other approaches, because it is easy, can be performed on an out-patient basis and leads to few complications [14, 27]. Our procedure has similarities to, and differences from, sclerotherapy described elsewhere $[12,14,16,21-$ $26,28]$. Similar to many other studies we used ethanol as sclerosing agent. It destroys the lining epithelium and leads to fibrotic obliteration which will impede production of cyst fluid [12]. Other sclerosing agents such as minocycline, tetracycline, or doxycycline destroy the lining epithelium by virtue of the highly acidic $\mathrm{pH}[14,15]$. These agents appeared to be similarly effective to ethanol [16]. A risk of the use of a sclerosing agent such as ethanol is marked sclerosis of the bile ducts when it is injected into a cyst that communicates with the biliary tree [12]. Therefore some authors argue that fluoroscopy should be used prior to instillation of ethanol $[12,16,22,23,25,28,29]$. We treated superficially located cysts that are not likely to communicate with the biliary tree, hence avoiding the need for verification by fluoroscopy. There is lack of objective data concerning optimum exposure time. Some authors instill ethanol for prolonged period but we chose a limited exposure time in order to limit the chances for complications $[12,14,16,22-26]$. This is supported by another study that elected to leave a catheter for drainage after the sclerotherapy. The sclerotherapy was repeated if more than $10-15 \mathrm{ml}$ cyst fluid was produced. In contrast with our findings, this study reports complications such as infection and pleural fluid effusion [16]. Most likely, these complications could have been avoided if the catheter was removed immediately after sclerotherapy. Several studies reported that the patients need to be turned over to various positions, in order to permit ethanol to come into contact with all surfaces of the cyst cavity $[12,14,15,22,23,25$, 26, 28]. This procedure was not part of our applied technique.

Aspiration-sclerotherapy is indicated in patients with symptoms that are associated with large liver cysts $(>5 \mathrm{~cm})$ and/or dominant cysts.

Other patients, especially those with multiple small cysts scattered throughout the liver parenchyma, are candidates for other therapeutic options-open or laparoscopic liver cyst fenestration, partial liver resection, or liver transplantation.
The choice between these modalities is made on the basis of the location of cysts, volume of the liver, and surgical experience. Open fenestration of cysts is more effective in terms of volume reduction, but the morbidity of laparoscopic fenestration is lower than that of the open procedure [30]. Patients with livers with a dominantly affected liver segment might be candidates for a partial liver resection, but the morbidity rate is higher than for the other procedures. Finally, liver transplantation is indicated if other therapies are no option or failed and if the patient is severely incapacitated by the large volume of the liver [10].

Acknowledgements We thank the Department of Radiology and the Department of Radiation Oncology of the University Medical Centrum St. Radboud, Nijmegen, The Netherlands, for volume measurement. This work was supported by The Nederlandse Vereniging voor Hepatologie (NVH). Financial support: Joost PH Drenth is a recipient of a ZON-MW VIDI research grant.

Open Access This article is distributed under the terms of the Creative Commons Attribution Noncommercial License which permits any noncommercial use, distribution, and reproduction in any medium, provided the original author(s) and source are credited.

\section{References}

1. Gaines PA, Sampson MA (1989) The prevalence and characterization of simple hepatic cysts by ultrasound examination. Br J Radiol 62:335-337

2. Caremani M, Vincenti A, Benci A, Sassoli S, Tacconi D (1993) Ecographic epidemiology of non-parasitic hepatic cysts. J Clin Ultrasound 21:115-118

3. Carrim ZI, Murchison JT (2003) The prevalence of simple renal and hepatic cysts detected by spiral computed tomography. Clin Radiol 58:626-629

4. Qian Q, Li A, King BF, Kamath PS, Lager DJ, Huston J III, Shub C, Davila S, Somlo S, Torres VE (2003) Clinical profile of autosomal dominant polycystic liver disease. Hepatology 37:164-171

5. Drenth JP, te Morsche RH, Smink R, Bonifacino JS, Jansen JB (2003) Germline mutations in PRKCSH are associated with autosomal dominant polycystic liver disease. Nat Genet 33:345-347

6. Davila S, Furu L, Gharavi AG, Tian X, Onoe T, Qian Q, Li A, Cai Y, Kamath PS, King BF, Azurmendi PJ, Tahvanainen P, Kaariainen H, Hockerstedt K, Devuyst O, Pirson Y, Martin RS, Lifton RP, Tahvanainen E, Torres VE, Somlo S (2004) Mutations in SEC63 cause autosomal dominant polycystic liver disease. Nat Genet 36:575-577

7. Torres VE, Harris PC (2007) Polycystic kidney disease: genes, proteins, animal models, disease mechanisms and therapeutic opportunities. J Intern Med 261:17-31

8. Desmet VJ (1998) Ludwig symposium on biliary disorders-part I. Pathogenesis of ductal plate abnormalities. Mayo Clin Proc 73:80-89

9. Lazaridis KN, Strazzabosco M, Larusso NF (2004) The cholangiopathies: disorders of biliary epithelia. Gastroenterology 127:1565-1577

10. Everson GT, Taylor MR, Doctor RB (2004) Polycystic disease of the liver. Hepatology 40:774-782

11. Garcea G, Pattenden CJ, Stephenson J, Dennison AR, Berry DP (2007) Nine-year single-center experience with nonparasitic liver cysts: diagnosis and management. Dig Dis Sci 52:185-191 
12. Bean WJ, Rodan BA (1985) Hepatic cysts: treatment with alcohol. AJR Am J Roentgenol 144:237-241

13. Saini S, Mueller PR, Ferrucci JT Jr, Simeone JF, Wittenberg J, Butch RJ (1983) Percutaneous aspiration of hepatic cysts does not provide definitive therapy. AJR Am J Roentgenol 141:559-560

14. Moorthy K, Mihssin N, Houghton PW (2001) The management of simple hepatic cysts: sclerotherapy or laparoscopic fenestration. Ann R Coll Surg Engl 83:409-414

15. Tokunaga K, Teplick SK, Banerjee B (1994) Simple hepatic cysts. First case report of percutaneous drainage and sclerosis with doxycycline, with a review of literature. Dig Dis Sci 39:209-214

16. van Sonnenberg E, Wroblicka JT, D'Agostino HB, Mathieson JR, Casola G, O'Laoide R, Cooperberg PL (1994) Symptomatic hepatic cysts: percutaneous drainage and sclerosis. Radiology 190:387-392

17. Bovenschen HJ, Janssen MJ, van Oijen MG, Laheij RJ, van Rossum LG, Jansen JB (2006) Evaluation of a gastrointestinal symptoms questionnaire. Dig Dis Sci 51:1509-1515

18. Emiroglu R, Coskun M, Yilmaz U, Sevmis S, Ozcay F, Haberal M (2006) Safety of multidetector computed tomography in calculating liver volume for living-donor liver transplantation. Transplant Proc 38:3576-3578

19. Andersen V, Sonne J, Sletting S, Prip A (2000) The volume of the liver in patients correlates to body weight and alcohol consumption. Alcohol Alcohol 35:531-532

20. Sandrasegaran K, Kwo PW, DiGirolamo D, Stockberger SM Jr, Cummings OW, Kopecky KK (1999) Measurement of liver volume using spiral CT and the curved line and cubic spline algorithms: reproducibility and interobserver variation. Abdom Imaging 24:61-65

21. Kakizaki K, Yamauchi H, Teshima S (1998) Symptomatic liver cyst: special reference to surgical management. J Hepatobiliary Pancreat Surg 5:192-195
22. Larssen TB, Rosendahl K, Horn A, Jensen DK, Rorvik J (2003) Single-session alcohol sclerotherapy in symptomatic benign hepatic cysts performed with a time of exposure to alcohol of 10 min: initial results. Eur Radiol 13:2627-2632

23. Tikkakoski T, Makela JT, Leinonen S, Paivansalo M, Merikanto J, Karttunen A, Siniluoto T, Kairaluoma MI (1996) Treatment of symptomatic congenital hepatic cysts with single-session percutaneous drainage and ethanol sclerosis: technique and outcome. J Vasc Interv Radiol 7:235-239

24. Andersson R, Jeppsson B, Lunderquist A, Bengmark S (1989) Alcohol sclerotherapy of non-parasitic cysts of the liver. Br J Surg 76:254-255

25. Kairaluoma MI, Leinonen A, Stahlberg M, Paivansalo M, Kiviniemi H, Siniluoto T (1989) Percutaneous aspiration and alcohol sclerotherapy for symptomatic hepatic cysts. An alternative to surgical intervention. Ann Surg 210:208-215

26. Tanis AA, Rosekrans PA, Wiggers RH, Ouwendijk RJ (1994) Percutaneous drainage of benign nonparasitic liver cysts. Ned Tijdschr Geneeskd 138:859-861

27. Lee YR, Lee KB (2003) Ablation of symptomatic cysts using absolute ethanol in 11 patients with autosomal-dominant polycystic kidney disease. Korean J Radiol 4:239-242

28. Ferris JV (2003) Serial ethanol ablation of multiple hepatic cysts as an alternative to liver transplantation. AJR Am J Roentgenol 180:472-474

29. Larssen TB, Jensen DK, Viste A, Horn A (1999) Single-session alcohol sclerotherapy in symptomatic benign hepatic cysts. Longterm results. Acta Radiol 40:636-638

30. van Keimpema L, Ruurda JP, Ernst MF, van Geffen HJ, Drenth JP (2007) Laparoscopic fenestration of liver cysts in polycystic liver disease results in a median volume reduction of $12.5 \%$. J Gastrointest Surg. doi:10.1007/s11605-007-0376-8 